\title{
Family satisfaction with a Children and Youth Psychosocial Care Center Service
}

\author{
Santos Larissa; Bandeira Marina; Pollo Tatiana
}

\section{INDRODUCTION}

The family is one of the key caregivers of psychiatric patients but has been rarely included in the process of evaluating satisfaction with mental health services, especially regarding child and adolescent services.

The objective of this research was to evaluate the family caregivers' satisfaction with a Child and Adolescent Psychosocial Care Center and its associated factors.

\section{METHODS}

It is an evaluative, summative research. It also consists of a correlational and cross-sectional study. It was performed in Brazil in a municipality in the interior of Minas Gerais.

Sixty-five family members were interviewed, using the Family Satisfaction Assessment Scale with the Mental Health Services (SATIS/Br) and a sociodemographic questionnaire.

\section{RESULTS}

The results showed that the family members had scores between satisfied and very satisfied with the service (score 4.64), specially concerning the dimension of satisfaction with the treatment results. The multivariate analysis pointed to the factors associated with satisfaction, in particular variables related to cargivers' conditions of life. It is concluded that family caregivers need support and guidance from services, specially a subgroup with difficult life conditions.

Predictors of higher level of satisfaction of family members were, in decreasing order of importance:

$\checkmark$ when the family member did not feel ill because of taking care of the patient; $(\mathrm{p}>0.005)$

$\checkmark$ When the family member was younger; $(\mathrm{p}>0.014)$ $\checkmark$ thought that the help of the service was sufficient; $(\mathrm{p}>0.045)$

$\checkmark$ did not take care of other sick people in the house; $(\mathrm{p}>0.090)$

$\checkmark$ had leisure activity; $(\mathrm{p}>0.135)$

$\checkmark$ the patient had not repeated in the school year. $(\mathrm{p}>0.204)$

These results indicate that family member variables contributed more to their service satisfaction than patient variables.

\section{DISCUSSION}

In the sample $89.2 \%$ of family caregivers were female. This result is in agreement with other studies that also found the female figure as the main family caregiver and for cultural reasons would present greater acceptance in relation to the care offered by health services.

Regarding patient care, there was a higher prevalence for males with $66.2 \%$ of the sample, confirming other Brazilian and international studies on mental health with children. This difference is due to the fact that girls have fewer symptoms of aggression / impulsivity and conduct (externalizing behaviors), causing less discomfort to families and school, so that they are less referred to treatment. Satisfaction with the third dimension (confidentiality and privacy) was significantly lower than for treatment outcomes.

\section{CONCLUSION}

The data allow us to conclude that family members 'characteristics were more predictive of their satisfaction with the service than patients' characteristics. 